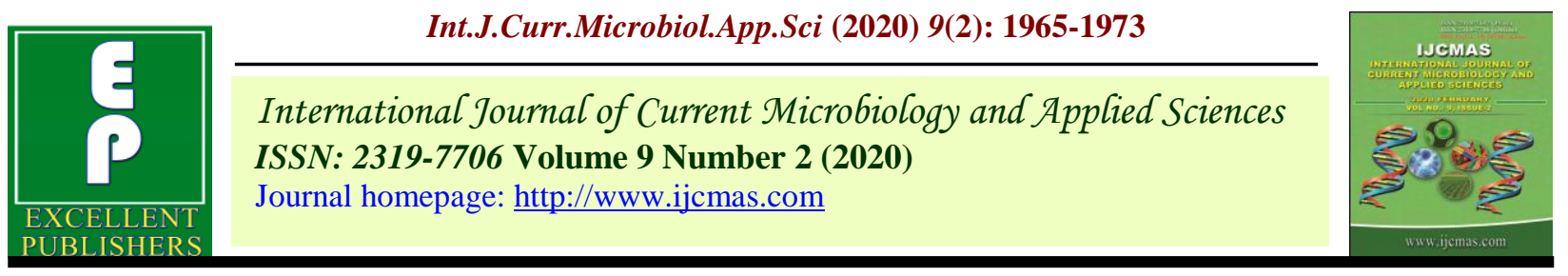

Original Research Article

https://doi.org/10.20546/ijcmas.2020.902.224

\title{
Development of 'Goatvision'- An Android based Mobile Application for Goat Farmers
}

\author{
V.V. Sulakhe, S. R. Kolhe*, M. P. Nande, S. M. Bhalerao and A. Y. Doiphode \\ Department of Veterinary and Animal Husbandry Extension Education, KNP College of \\ Veterinary Science, Shirwal, Dist. Satara, Maharashtra \\ *Corresponding author
}

\begin{tabular}{|l|}
\hline Keyw or d s \\
Mobile app, Goat \\
farming, ICT
\end{tabular}

\section{A B S T R A C T}

The present study entitled "Development of 'GoatVision'- An Android Based Mobile Application for Goat Farmers" was conceptualized with the objective of developing an android based mobile application in local language. An exploratory research design was used for the present study. A total of 60 respondents were selected by purposive random sampling from Pune and Satara districts of Maharashtra to assess the information needs of the goat farmers and to study the effectiveness, perceived utility of developed mobile application. The data was collected through structured questionnaire and was administered to the respondents through personal interview method. On the basis of information needs of goat farmers, 'GoatVision'- an android based mobile application was developed on feeding and health care practices. After development of mobile application, it was again tested to see its effectiveness. The results revealed that the majority of goat farmers had perceived the information to be very effective in enhancing their knowledge regarding feeding and health care practices $(56.67 \%)$, about 50 percent of the respondents opined that the content was appropriate to the topic presented, 85 percent perceived it to be presented in a precise way, 65 percent felt that it was 'very simple' to understand and 50 percent of the respondents opined that the overall look was good and, has the ability to arouse curiosity and interest (75\%). It was perceived to be highly useful by 70.00 percent of the respondents. The android based mobile application was viewed as a useful tool by the goat farmers and many such apps can be designed in local language to deliver the information in the field of animal husbandry in the simplest manner which would be proved to be benignant for the livestock owner.

\section{Introduction}

Information and Communication Technology (ICT) expands physical time. It has a lot to do with one's own choice. It is a challenge that will constantly be renewed in one's journey of discovery and self-discovery. It is the integration of information processing, computing and communication technologies. The ICT is also being used in the country in many ways for animal health management, disease control; feeding of livestock, herd management, for marketing of milk, awareness, and information dissemination, tentative diagnosis of animal diseases and in first aid measures. Modern information and 
communication technologies have created a "global village," and it has increased its priority in people's lives. Furthermore, it is expected that this drift will continue, to the extent that ICT literacy will become a functional prerequisite for people's work, social, and personal lives. Among ICTs, mobile telephony has materialized as the smart technology of choice and has been regarded as the extensively accessed tool among the farmers for communication and also accessing agriculture-related information. Our country has encountered huge economic losses due to lack of knowledge on improved goat rearing practices. Feeding alone donates a major part in the cost of production and plays a vital role in keeping the growth rate constant. Likewise, health directly affects the production capacity and reproducing ability of goats and thus, increases expenditure on medicine. Goat farmers are in real need of timely, accurate and relevant information about feeding and health care practices at their doorstep. Improved decisions can be made by the farmers on their fingertips. Besides, location specific information in local language can help farmer in solving their problems to keep their flock disease free and healthy. Also, there are very less number of studies on mobile applications in the Animal Husbandry in India. Thus, an android based mobile application can be very much useful in disseminating the knowledge and information to the goat farmers, which is easily understandable by the farmers, by accessing the required, latest and timely information. Keeping all these facts in view, the present study has been taken up with the objective to assess and prioritize the information needs of goat farmers, to develop an android based mobile application on feeding and health care practices and to study the effectiveness, perceived utility and constraints encountered in accessibility of the developed mobile application.

\section{Materials and Methods}

Exploratory research design was used for the present study. A total of 60 respondents were selected by purposive random sampling from Pune and Satara districts of Maharashtra to assess the information needs of the goat farmers. After the assessment of information needs of goat farmers, it was revealed that information needs on feeding and health care practices are on priority. This information was then prioritized and an android based mobile application 'GoatVision' was developed in local language i.e. Marathi on feeding and health care practices of goat farming. The data was collected through structured questionnaire and was administered to the respondents through personal interview method. Data generated were then subjected to statistical analysis using appropriate statistical methods like frequency, percentage, mean and standard deviation. To study the effectiveness and perceived utility of the developed mobile application, it was tested among previously selected 60 respondents by personal interview method. An interview schedule containing all the variables was prepared in consultation with the experts in the field of Veterinary and Animal Husbandry, to acquire the set objectives of the study. Pre- testing of the interview schedule was done to eliminate errors, if any.

\section{Results and Discussion}

\section{Information needs of goat farmers}

The information needs of each respondent regarding various aspects of goat farming practices i.e. breeding, feeding, management and health care was analyzed after discussion with the respondent. On the basis of respondent's knowledge on above aspects their information needs were identified and prioritized. The distribution of the respondents according to the information 
needs of the goat farmers is presented in Table 1 .

Table 1 depicted that information need on breeding practices by the respondents were (60\%) 'Needed' and (40\%) 'Most Needed'. None of the respondents considered it as 'Least Needed' information. Information on feeding practices was considered to be 'Most Needed' by three fourth $(75 \%)$ of the respondents, followed by 25.00 percent who considered it as 'Needed' information. Nearly half of the respondents $(51.66 \%)$ 'Needed' information on management practices followed by 33.33 percent and 15.00 percent of the respondents who considered it as 'Most Needed' and 'Least Needed' information respectively. Majority of the respondents (70.00\%) considered information on health care practices as 'Most Needed', followed by 30.00 percent who considered it as 'Needed' information. None of the respondents considered it as 'Least Needed' information.

The data from Table 1 is summarized below to calculate and prioritize the overall preferences of respondent for information on various aspects of goat farming practices. For the development of 'GoatVision'- an android based mobile application, only those goat farming practices were considered, who got first choice of the respondent i.e. under 'Most Needed' category. The final preference ranking is described in Table 2

It is clearly evident from Table 2 that 'Feeding practices' (Rank I) and 'Health care practices' (Rank II) was the most preferred and prime area for information needs by the goat farmers. These findings are in line with Upendrakumar et al., (2014) and Sinha et al., (2016).

Feeding alone donates a major part in the cost of production and plays a vital role in keeping the growth rate constant. Proper balanced feed helps to reach puberty in an early stage of life and improves fecundity and prolificacy. Also, at times, it is difficult to manage goats during draught conditions. So they desired to know more about the storage of feed and feed stuffs during any natural or manmade calamity to help feed their goats. These respondents intended to tackle all these concerns of feeding for making goat enterprise a sustainable and efficiently feasible business. The information on feeding practices is mainly obtained through the various information sources which were not much reliable as they lack credibility. So, the farmers needed such credible information through mobile apps which can help in reducing the overall expenditure on feeding by adopting various scientific methods. The reason for giving prime importance to health care could be that the health directly affects the production capacity and reproducing ability of goats and thus, increases expenditure on medicine, consultation charges and reduces their growth and production. These respondents might want to keep their flock disease free and healthy by isolation of suspected animals and regular vaccination and deworming. They had a great need for the information on health care to take up the precautionary measure and maintain good productive animals. Moreover, these respondents might want to make goat farming feasible and economically beneficial by cutting down all the cost on feeding and health care practices as much as possible. Thus, while developing the mobile app, the feeding and health care aspect of goat farming has to be considered. Hence, on the basis of these prioritized needs, an android based mobile application was developed on feeding and health care practices.

\section{Development of 'GoatVision'- an android based mobile application for goat farmers}

An android based mobile application'GoatVision' has been designed and developed by considering the most important 
aspect required by the goat farmers' i.e. feeding and health care practices in local language of Marathi. The primary goal of developing an android based mobile application was to develop an informative and user friendly mobile application that will be able to focus on the feeding and health care practices of goat farming.

The mobile application was developed in three phases. In the first phase, information needs of the goat farmers were studied in the research area. After identification and prioritization of information needs of the goat farmers, second phase instigated, where it contained master outline of content. For content development, an extensive literature search was done on feeding and health care practices of goat farming. All available sources were consulted such as research articles, booklets, websites, newspaper articles, books, etc for developing contents on feeding and health care practices of goat faming. All the resources needed were integrated with the help of various software tools. Microsoft word was used for typing and editing of text. Contents were developed in local dialect i.e. Marathi. This step also involved collection of pictures relevant to the content and with the help of Adobe Photoshop and Photo and Picture Re-sizer the images were edited, to give a clear understanding for less educated as well as illiterate farmers. Then, this information was investigated, classified, organised and stored in consultation with selected livestock farmers, field veterinarians and the experts in the field of animal husbandry.

The third and the final step involved software development which in association with Reformist India, IT Solutions Pvt. Ltd., modules were developed and the idea was conceptualized. Then after wire framing and designing, 'GoatVision' - an android based mobile application was developed, which provides a complete package of information related to feeding and health care practices of goat farming at farmers' finger tips.

This app is an android based mobile application in local dialect i.e. Marathi, available in APK file format (storage space of 7.10 MB) for its installation and distribution. GoatVision app will be available on Google PlayStore for public use soon after the fulfilment of technical requirements and legal permission of Maharashtra Animal and Fishery Sciences University, Nagpur. The mobile application could effortlessly and liberally be downloaded to any android based smart phone or tablets. This app works offline once installed and could be transferred to other smart phones using "Bluetooth" and "ShareIt" applications or via E-mail. The app consists of hardware part (an android based smart phone) and software part (content on feeding and health care practices for goat farmers prepared in consultation with selected livestock farmers, field veterinarians and the experts in the field of animal husbandry).

The first page of the mobile application asks for Mobile Number for registration. After entering the Mobile Number, an OTP is generated and the Mobile Number is confirmed. After completion of the registration process, the page leads to the 'Home page' of the mobile app. The home page contains three major nodes related to different aspects of goat farming, which links to major content groups as Goat Farming, Feeding Practices in Goats and Health Care Practices in Goats. The App drawer on the top- left corner of the home page leads to different navigations viz., Goat Farming, Feeding Practices in Goats, Health Care Practices in Goats, Project Team, Contacts (Helpline, Address and Website links), Feedback and Disclaimer. Each major topic consists of sub headings and contents in the form of text supported by suitable visuals in 
the form of images. The goat farming page deals with the benefits of goat farming and general information about the goats. The feeding practices of goats deals in details about the digestive system of goats; nutritional requirement of goats; importance of vitamins and minerals in goats feed; feeding management of goats; practical feeding of goats and their feeding schedule (kids, does and bucks); feed formulation of balanced ration; importance of concentrate mixture in goats feed; formulation and composition of homemade concentrate mixture; feeding of bucks for Bakra Eid; nutrient component of feedstuffs; unconventional feedstuffs; storage of fodder during scarcity of feed and feedstuffs (hydroponics, azolla cultivation and making) and urea treatment of fodder.

The health care practices of goats deals with the signs of healthy and sick goats; general information on various diseases encountered in goats, their symptoms and, preventive and first aid measures (Viral diseases, bacterial diseases, parasitic diseases and skin diseases). It also provides information on goat poisoning and toxicity; kid mortality; preventive measures to avoid contagious diseases and vaccination- deworming schedule.

Assessment of effectiveness and perceived utility of 'GoatVision'- an android based mobile application

\section{Effectiveness of mobile app in enhancing knowledge}

Table 3 indicates that, 56.67 percent respondents perceived 'GoatVision' to be very effective in enhancing the knowledge regarding feeding and health care practices, while 43.33 percent stated it is effective. Not a single respondent felt that, it is not effective for knowledge enhancement. These findings are in line with Belakeri et al., (2017) that the developed fodder mobile app proved to be effective in terms of knowledge gain on fodder production among livestock farmers of Karnataka. Similar findings were recorded by Roy (2013) that 91.11 percent of the respondents perceived it to be 'highly effective in enhancing knowledge', followed by 8.89 percent of the respondents who perceived it as moderately effective. Thus, the results certainly show that the information source can be a very good tool to augment the knowledge of the respondents.

\section{Opinion of the respondents about mobile app}

During the data collection, respondents were asked about their opinion on relevancy, preciseness, simplicity, visual quality and perceived utility of 'GoatVision' and the results are presented in Table 36 to 40.

\section{Relevance of contents}

It is evident through Table 4 that, majority $(50.00 \%)$ of respondents were of the opinion that the contents of the 'GoatVision' are appropriate to the topic presented, followed by 45.00 percent said that it was relevant. But only 5.00 percent respondents felt it was not relevant to the topic, which may be due their higher knowledge level and their requirement for more specific information about certain aspect of the topic. Similar finding was recorded by Roy (2013) that more than half of the overall goat farmers $(54.44 \%)$ had the opinion that the contents of GHMIS are appropriate to the topic presented, followed by 40.00 percent respondents considered it as relevant and 5.56 percent opined it as not relevant.

\section{Preciseness of content}

Table 5 revealed that 85.00 percent of respondents felt that, the content of 
'GoatVision' had been presented in a precise way, while 8.33 percent felt it is very precise i.e. incompetent to understand the topic and try to seek more information. Similarly 6.66 percent respondents were of opinion that, the content can be further precise. The preciseness of the GHMIS studied by Roy (2013) revealed the remarks of goat farmers as: presented in a precise way $(56.67 \%)$ and very precise $(43.33 \%)$. Respondents who opined it very precise wanted more detailed information on storage of fodder. This could be attributed to the fact that they might be facing difficulties in fulfilling the feed requirement of goats during shortage of feed and feedstuffs.

\section{Simplicity of content}

For easy understanding of the subject, the content should be presented in a very simple and common language. The respondents were asked their opinion about the simplicity of the content of 'GoatVision'. As per Table 6, out of all the respondents, 65.00 percent of respondents felt that, it was very simple to understand and 30.00 percent of them told it is simple. However, only 5.00 percent of the respondents reported it is difficult and needs more clarification and simplification. Similar findings were observed by Roy (2013) that the information system was perceived to be very simple by majority $(65.56 \%)$ of the overall goat farmers, followed by simple (24.44\%) and little difficult (10.00\%). Thus, it proved to be easy in its operation, navigation and understanding of the content through simple local vernacular by the majority of the respondents.

Table.1 Distribution of respondents according to their information needs

\begin{tabular}{|c|c|c|c|}
\hline & & & $\mathrm{N}=60$ \\
\hline Sr. No. & Information needs & Frequency & Percentage \\
\hline 1. & \multicolumn{3}{|l|}{ Breeding practices } \\
\hline a. & Needed & 36 & 60.00 \\
\hline b. & Most Needed & 24 & 40.00 \\
\hline \multirow[t]{2}{*}{ c. } & Least Needed & 00 & 0.00 \\
\hline & Total & 60 & 100.00 \\
\hline 2. & \multicolumn{3}{|l|}{ Feeding practices } \\
\hline a. & Needed & 15 & 25.00 \\
\hline b. & Most Needed & 45 & 75.00 \\
\hline \multirow[t]{2}{*}{ c. } & Least Needed & 00 & 0.00 \\
\hline & Total & 60 & 100.00 \\
\hline 3. & \multicolumn{3}{|l|}{ Management practices } \\
\hline a. & Needed & 31 & 51.66 \\
\hline b. & Most Needed & 20 & 33.33 \\
\hline \multirow[t]{2}{*}{ c. } & Least Needed & 09 & 15.00 \\
\hline & Total & 60 & 100.00 \\
\hline 4. & \multicolumn{3}{|l|}{ Health care practices } \\
\hline a. & Needed & 18 & 30.00 \\
\hline b. & Most Needed & 42 & 70.00 \\
\hline \multirow[t]{2}{*}{ c. } & Least Needed & 00 & 0.00 \\
\hline & Total & 60 & 100.00 \\
\hline
\end{tabular}


Table.2 Ranking wise information needs of goat farmers

\begin{tabular}{|l|l|l|l|}
\hline Sr. No. & Goat farming practices & Percentage & Rank \\
\hline 1. & Feeding practices & $\mathbf{7 5 . 0 0}$ & I \\
\hline 2. & Health care practices & $\mathbf{7 0 . 0 0}$ & II \\
\hline 3. & Breeding practices & 40.00 & III \\
\hline 4. & Management practices & 33.33 & IV \\
\hline
\end{tabular}

Table.3 Opinion of respondents about effectiveness of 'GoatVision' in enhancing knowledge

\begin{tabular}{|l|l|l|l|}
\hline Sr. No. & Category & Frequency & Percentage \\
\hline 1. & Very Effective & 34 & 56.67 \\
\hline 2. & Effective & 26 & 43.33 \\
\hline 3. & Not Effective & 00 & 0.00 \\
\hline & Total & 60 & 100.00 \\
\hline
\end{tabular}

$\mathrm{N}=60$

Table.4 Opinion of respondents about relevancy of contents of 'GoatVision'

\begin{tabular}{|l|l|l|l|}
\hline Sr. No. & Category & Frequency & Percentage \\
\hline 1. & Appropriate & 30 & 50.00 \\
\hline 2. & Relevant & 27 & 45.00 \\
\hline 3. & Not Relevant & 3 & 5.00 \\
\hline & Total & 60 & 100.00 \\
\hline
\end{tabular}

Table.5 Opinion of respondents about preciseness of content of 'GoatVision'

\begin{tabular}{|l|l|l|l|}
\hline Sr. No. & Category & Frequency & Percentage \\
\hline 1. & Very Precise & 5 & 8.33 \\
\hline 2. & Precise & 51 & 85.00 \\
\hline 3. & Not Precise & 4 & 6.66 \\
\hline & Total & 60 & 100.00 \\
\hline
\end{tabular}

Table.6 Opinion of respondents about simplicity of content of 'GoatVision'

\begin{tabular}{|l|l|l|l|}
\hline Sr. No. & Category & Frequency & Percentage \\
\hline 1. & Very Simple & 39 & 65.00 \\
\hline 2. & Simple & 18 & 30.00 \\
\hline 3. & Difficult & 3 & 5.00 \\
\hline & Total & 60 & 100.00 \\
\hline
\end{tabular}


Table.7 Opinion of respondents about visual quality of contents of 'GoatVision'

\begin{tabular}{|l|l|l|l|}
\hline Sr. No. & Category & Frequency & Percentage \\
\hline 1. & Very Good & 22 & 36.66 \\
\hline 2. & Good & 30 & 50.00 \\
\hline 3. & Poor & 8 & 13.33 \\
\hline & Total & 60 & 100.00 \\
\hline
\end{tabular}

Table.8 Opinion of respondents about arousal of curiosity and interest of contents of 'GoatVision'

\begin{tabular}{|l|l|l|l|}
\hline Sr. No. & Category & Frequency & Percentage \\
\hline 1. & Very Effective & 15 & 25.00 \\
\hline 2. & Effective & 45 & 75.00 \\
\hline 3. & Not Effective & 00 & 0.00 \\
\hline & Total & 60 & 100.00 \\
\hline
\end{tabular}

Table.9 Opinion of respondents about perceived utility of 'GoatVision'

\begin{tabular}{|l|l|l|l|}
\hline Sr. No. & Category & Frequency & Percentage \\
\hline 1. & Very Useful & 42 & 70.00 \\
\hline 2. & Useful & 18 & 30.00 \\
\hline 3. & Not Useful & 00 & 0.00 \\
\hline & Total & 60 & 100.00 \\
\hline
\end{tabular}

\section{Visual quality of contents}

To hold the attention and interest of the learner, a visual appeal is obligatory. The respondents were asked about the visual quality of the content such as simplicity of text and the interface, clarity of visuals used, background and text contrast and overall appearance of the mobile app.

Table 7 reveals that majority $(50.00 \%)$ of the respondents opined the visual quality of 'GoatVison' as good, followed by 36.66 percent opined it as very good and only 15 percent opined it as poor. The respondents who opined that it was poor wanted more images in the mobile app related to the symptoms of the diseases encountered in goats. These findings coincided with the findings of Teza and Sharma (2016) and Roy (2013) that almost all of the goat farmers $(88.89 \%)$ opined the look of the software GHMIS as very good, followed by 11.11 percent opined it as good.

\section{Arousal of curiosity and interest of respondent}

As per Table 8 shows 75.00 percent respondent reported that, 'GoatVision' will be effective and has ability to arouse curiosity and interest which is mainly due to use of pictures in the mobile app, while 25.00 percent felt it is very effective. None of the respondent found it ineffective. These findings are in line with the findings of Teza and Sharma (2016) and Roy (2013) that 81.11 percent of the overall goat owners reported 
that GHMIS will be very effective while 18.89 percent felt it is effective.

\section{Perceived utility of 'GoatVision'}

'GoatVision' is developed with the objective of giving information on feeding practices and health aspects of animal for goat farmers, especially on diseases of the goats, so that he can make tentative diagnosis at his level and take decision as early as possible to avoid economic losses. It also envelopes the topics like preventive and first aid measures on various common diseases and disorders encountered in goats. After showing the mobile app to the respondent, their opinion was asked about the overall performance and utility of GoatVision. The result shows (Table 9) that, 70.00 percent respondents perceived GoatVision as very useful, and 30.00 percent said it is useful to them for decision making. No one felt it as useless. Similar findings were recorded by Roy et al., (2014) and Sharma et al., (2017).

In the present study, feeding and health care aspects were identified as the most needed requirements of the goat farmers in terms of information. 'GoatVision' app was found suitable, appealing, informative, accessible, precise, relevant and easy source of information for the goat farmers. The development of information content in the form of an android based mobile application will be most convenient, cheapest and effective future mode of information dissemination. In the era of digitalization and ICT, development of such need based, informative mobile applications on other aspects of scientific animal husbandry practices in local language are warranted which may become important source of information to the farming community.

\section{References}

Sinha, S. K., M. Chander, B. Mohan and K. Pachiyappan, 2016, Information Needs of Goat Rearing Farmers in Mathura District. Ind. J.of Vet. Sci. and Biotechnology. 11 (4): 30- 34.

Upendrakumar M.L., Reager, S. Ranveer, G. Balwada and D. Chaturvedi (2014) Economics of goat farming under traditional low input production systems in Bhikaner dsitrict. Asian J. Ani. Sci. 9(2):160-163.

Teza, J. and G.R.K. Sharma, 2016, Quality of Mobile Apps as an Extension Service Delivery Tool to Livestock Based WSHG Members. Int. J. of Sci. and Research. 5 (3): 2141-2143.

Sharma, Y., B.K. Dak and N. Acharya, 2017, Emerging Trends in mobile apps market and their potential impact on mobile users engagement in the global economy. Annual Res. J. of Symbiosis Centre for Management Studies, Pune. 5: 61-81.

Roy, R., 2013, Development of a Need Based Interactive Goat Health Management Information System. Ph.D thesis submitted to the Deemed University, IVRI, Izatnagar, India.

Belakeri, P., K. Satyanarayan, V. Jagadeeswary, S. Yathiraj, K. C. Veeranna and Y. B. Rajeshwari, 2017, Effectiveness of Mobile App on Fodder Production in Terms of Knowledge Gain among Livestock Farmers of Karnataka. Ind. Res. J. Ext. Edu. 10-15.

\section{How to cite this article:}

Sulakhe, V.V., S. R. Kolhe, M. P. Nande, S. M. Bhalerao and Doiphode, A. Y. 2020. Development of 'Goatvision'- An Android based Mobile Application for Goat Farmers. Int.J.Curr.Microbiol.App.Sci. 9(02): 1965-1973. doi: https://doi.org/10.20546/ijcmas.2020.902.224 